\title{
CARGOS E SALÁRIOS DOS ENGENHEIROS DE PESCA: ESTUDO DE CASO A PARTIR DE EDITAIS DE CONCURSOS PÚBLICOS NO ESTADO DO PARÁ
}

\author{
VIANA, Jeanderson da Silva ${ }^{1}$ \\ SILVA, Leonilton Rodrigues Barbosa $\mathrm{da}^{2}$ \\ PEREIRA, Mayara da Costa ${ }^{3}$ \\ ABREU, Geovana Monteiro ${ }^{4}$ \\ SANTOS, Marcos Antônio Souza dos 5 \\ BRABO, Marcos Ferreira ${ }^{6}$
}

\begin{abstract}
RESUMO: O estado do Pará formou até o último ano, 487 engenheiros de pesca. Uma parte desses profissionais estão inseridos em diversas atividades do ramo aquícola e pesqueiro, dentre estes, o setor público merece destaque. Os órgãos públicos não realizam o pagamento conforme o piso salarial proposto por lei. No âmbito municipal, a baixa remuneração desmotiva o engenheiro de pesca em exercer suas tarefas. No âmbito estadual, a falta de plano de carreira é motivo de insatisfação deste servidor público. No âmbito federal, as IES são a maioria e oferecem os maiores salários, porém o ingresso é restrito para quem possui pós-graduação. Em todas as esferas de Governo, há reinvindicações para aumento de salário e fortalecimento da associação de classe. As disparidades entre as remunerações nas esferas públicas paraenses estão muito além do reconhecimento profissional dos engenheiros de pesca, mas sim da ausência ou ineficiência de um planejamento estratégico para aproveitar da melhor maneira a produtividade destes profissionais e assim gerar maior arrecadação para autarquia.
\end{abstract}

Palavras-chave: Salário mínimo. Órgão público. Profissão. Engenharia de pesca.

\section{FISHING ENGINEERS 'CHARGES AND WAGES: CASE STUDY FROM EDICTS PUBLIC TENDER IN THE PARÁ STATE}

SUMMARY: The Para State formed until the last year, 487 fishing engineers. A part of these professionals are inserted in several aquaculture and fishing activities, among these, the public sector should be highlighted. Public agencies do not pay according to the minimum wage proposed by law. At the municipal sphere, the low remuneration discourages the fishing engineer from carrying out his tasks. At the state sphere, the lack of career plan is cause for dissatisfaction of this server public. At the federal sphere, the IES are the majority and offer the highest salaries, but admission is restricted to those who have a postgraduate degree. $\mathrm{n}$ all spheres of Government, there are claims for salary increase and strengthening of the class association. The disparities between remunerations in the public spheres of Para State go far beyond the professional recognition of fishing engineers, but rather the absence or inefficiency of a strategic plan to make the best use of the productivity of these professionals and thus generate higher tax revenue for autarchy.

Keywords: Minimum wage. Public agency. Profession. Fishing engineering.

\footnotetext{
${ }^{1}$ Engenheiro de Pesca pela Universidade Federal Rural da Amazônia (UFRA). Mestrando em Aquicultura na Universidade Federal de Santa Catarina (UFSC)

${ }^{2}$ Engenheiro de Pesca pela Universidade Federal Rural da Amazônia (UFRA). Mestrando em Aquicultura e Recursos Aquáticos Tropicais na UFRA, Brasil.

${ }^{3}$ Engenheira de Pesca pela Universidade Federal Rural da Amazônia (UFRA). Mestranda em Aquicultura e Recursos Aquáticos Tropicais na UFRA, Brasil.

${ }^{4}$ Engenheira de Pesca pela Universidade Federal Rural da Amazônia (UFRA)

${ }^{5}$ Engenheiro Agrônomo, Dr., Prof. de Economia Pesqueira na Universidade Federal Rural da Amazônia (UFRA).

${ }^{6}$ Engenheiro de Pesca, Dr., Professor de Economia Pesqueira da Universidade Federal do Pará (UFPA)
} 


\section{INTRODUÇÃO}

A produção aquícola do Brasil atingiu um valor estimado de $\mathrm{R} \$ 4,39$ bilhões para um total de 592,1 mil toneladas, com 483,2 mil toneladas sendo provenientes da piscicultura, 69,9 mil toneladas da carcinicultura marinha e 21 mil toneladas da malacocultura, no ano de 2015 (IBGE, 2016).No ano posterior, o valor da produção da aquicultura brasileira correspondeu a $R \$ 4,61$ bilhões, para um total de 593,8 mil toneladas, sendo que 507,1 mil toneladas foram oriundas da piscicultura, enquanto a carcinicultura marinha produziu 52,1 mil toneladas e a malacocultura 20,8 mil toneladas, aproximadamente (IBGE, 2017).

Porém, apesar do crescimento da aquicultura no mercado, os produtores ainda enfrentam diversos obstáculos no desenvolvimento da atividade, como: dificuldade de regularização ambiental dos empreendimentos; alto preço dos insumos; assistência técnica insuficiente; baixa qualificação profissional dos aquicultores; reduzidas opções de linhas de crédito e financiamento; pequenos preços pagos ao produto do aquicultor; dificuldade de acesso à tecnologia; limitações do mercado regional e mortalidade de organismos por enfermidades (KUBITZA, 2015). Neste cenário, o profissional especializado em aquicultura assume papel de destaque, uma vez que agrega um conhecimento técnico e científico que pode fortalecer o setor produtivo perante estes desafios do setor aquícola brasileiro.A necessidade desta mão de obra qualificada impulsionou o surgimento do curso de engenharia de pesca no Brasil.

Na década de 1960, o Governo Federal aprovou o Decreto Lei ${ }^{\circ} 221$, de 28 de fevereiro de 1967 que regulamentou o exercício da atividade pesqueira no Brasil e criou uma série de incentivos para estimular o desenvolvimento deste setor produtivo no país. Com isso, houve uma carência de profissionais capacitados para suprir as demandas que surgiam do ramo aquícola e pesqueiro, e assim, a Universidade Federal Rural de Pernambuco (UFRPE) aprovou a criação do primeiro curso de Engenharia de Pesca do Brasil (BRASIL, 1967; SOARES; HAZIN, 2010).

A profissão foi reconhecida legalmente por meio da Resolução n. 218, do Conselho Federal de Engenharia, Arquitetura e Agronomia (CONFEA), de 29 de junho de 1973, para fins de regulamentação, em que o profissional pode desenvolver atividades referentes ao cultivo, pesca, gestão e beneficiamento dos organismos aquáticos (CONFEA,1983), e atualmente, todas as regiões do país possui uma Instituição de Nível Superior (IES) que oferece vagas no curso de engenharia de pesca. (ALMEIDA; SALES; SOARES, 2009).

No estado do Pará, a formação de profissionais compete às IES: a Universidade Federal do Pará (UFPA), a Universidade Federal do Oeste do Pará (UFOPA) e a Universidade Federal Rural da Amazônia (UFRA). Até o ano de 2017, foram graduados 487 engenheiros de pesca (INEP, 2017). 
No que se refere aos recursos pesqueiros, o estado paraense foi o maior produtor nacional de pescado oriundo do extrativismo em 2011 com um total de 142,9 mil toneladas, mas ainda apresenta uma produção aquém de seu potencial aquícola (BRASIL, 2013; IBGE, 2017). Dentre os responsáveis por este desempenho, a carência de assistência técnica aos produtores, a dificuldade de aquisição de insumos básicos e o elevado preço das rações comerciais assumem papel de destaque (BRASIL, 2013; DE-CARVALHO; SOUSA; CINTRA, 2013). Esta conjuntura reforça ainda mais a necessidade da valorização do engenheiro de pesca.

Em relação à inserção no mercado de trabalho deste profissional, o setor público merece destaque por proporcionar estabilidade financeira ao profissional. (MACEDO et al., 2016). Contudo, nas repartições do Governo, o engenheiro de pesca também exerce atividades vinculadas ao setor administrativo, como: planejamento setorial, operacionalização de políticas públicas e articulação com os atores sociais. Devido o advento destas demandas, exige-se um maior nível de qualificação do profissional para torna-lo mais competitivo.

No que diz respeito ao setor privado, o engenheiro de pesca pode atuar mediante consultorias técnicas ao setor aquícola/pesqueiro (licenciamento ambiental, elaboração de projetos, estudo de mercado, capacitação técnica, monitoramento e conservação ambiental) e executar tarefas nas indústrias pesqueiras e de beneficiamento do pescado (auditorias, investigação pesqueira, controle de qualidade do pescado e planejamento administrativo da empresa). Contudo, a instabilidade financeira do país reflete na elevada busca de adentrar no contexto produtivo por meio de cargos públicos (ALBRECHT; KRAWULSKI, 2011).

Os cargos criados no setor público são por intermédio de editais que determinam a quantidade vagas disponíveis, denominações e suas remunerações, e assim, demonstrar o vínculo jurídico que relaciona o ocupante à administração. Dessa forma, podem ser apresentados como um elo entre a gestão e o indivíduo (LIMA et al., 2015).

Entretanto, diversos estudos têm sido desenvolvidos em variadas áreas de atuação para caracterizar o perfil do profissional, apresentar a incompatibilidade entre as suas responsabilidades com o salário do profissional e reivindicar a implantação de gestão estratégica que visem estimular este trabalhador: nas refinarias de petróleo (LIMA, 2008), na saúde pública (CAVALCANTE; LIMA, 2013; SOARES et al., 2013), na educação pública (SILVA et al., 2017; FERNANDES et al., 2018; ARAÚJO;VIANNA, 2008); na agronomia (UMBURANAS et al., 2010) e na zootecnia e recursos pesqueiros ( ALMEIDA; SALES; SOARES, 2009; VÉLEZ; GALEANO; GAVIRIA, 2010). Contudo, ainda não há trabalhos que exponha a incompatibilidade entre a remuneração recebida e o piso salarial do engenheiro de pesca. 
Com isso, o objetivo do trabalho foi identificar os cargos e salários dos engenheiros de pesca na esfera pública paraense, a fim de verificar o salário ofertado frente ao salário estabelecido em Lei e comparar as remunerações entre as esferas do serviço público.

\section{METODOLOGIA}

Os dados para realização deste estudo foram obtidos por meio da análise de 15 editais dos processos seletivos (extraídos de sites governamentais) realizados pelas entidades públicas do setor pesqueiro e aquícolas paraense, nas três esferas de governo. Para complementar as informações obtidas, realizou-se visitas em algumas destas instituições para entrevistar os engenheiros de pesca (Tabela 1).

Tabela 1. Editais dos processos seletivos realizados pelos órgãos públicos do setor pesqueiro e aquícola, no estado do Pará, 2017.

\begin{tabular}{|c|c|c|}
\hline $\begin{array}{l}\text { Esferas de } \\
\text { Governo }\end{array}$ & $\begin{array}{l}\mathbf{N}^{\circ} \text { do } \\
\text { edital }\end{array}$ & Entidades públicas \\
\hline \multirow{8}{*}{ Municipal } & $01 / 2016$ & Prefeitura de São João da Ponta * \\
\hline & $01 / 2011$ & Prefeitura de Bragança * \\
\hline & $01 / 2011$ & Prefeitura de Óbidos \\
\hline & $01 / 2012$ & Prefeitura de Vigia \\
\hline & $01 / 2013$ & Prefeitura de Cametá \\
\hline & $01 / 2013$ & Prefeitura de Tailândia \\
\hline & $01 / 2015$ & Prefeitura de Monte Alegre \\
\hline & $01 / 2012$ & $\begin{array}{l}\text { Fundação Centro de Referência em Educação Ambiental Escola } \\
\text { Bosque } \operatorname{Prof}^{\circ} \text { Eidorfe Moreira (FUNBOSQUE) }\end{array}$ \\
\hline \multirow{2}{*}{ Estadual } & $01 / 2005$ & $\begin{array}{l}\text { Empresa de Assistência Técnica e Extensão Rural (EMATER/PA) } \\
*\end{array}$ \\
\hline & $01 / 2007$ & Secretaria de Estado de Pesca e Aquicultura (SEPAq) $* 1$ \\
\hline \multirow{5}{*}{ Federal } & $04 / 2014$ & Universidade Federal Rural da Amazônia (UFRA) * \\
\hline & $244 / 2011$ & Universidade Federal do Pará (UFPA/Campus Bragança) * \\
\hline & $04 / 2015$ & $\begin{array}{l}\text { Instituto Federal de Educação, Ciência e Tecnologia do Pará } \\
\text { (IFPA/Campus Castanhal) }\end{array}$ \\
\hline & $46 / 2017$ & Universidade Federal do Oeste do Pará (UFOPA) \\
\hline & $01 / 2013$ & Superintendência do Desenvolvimento da Amazônia (SUDAM) \\
\hline
\end{tabular}


Durante a análise dos documentos, foi considerado somente o vencimento base vinculado ao cargo de engenheiro de pesca, conforme Lei Federal n. 8.112 de 1990 e Lei Estadual n. 5.810 de 1994, tendo considerado o salário bruto. Este vencimento corresponde à retribuição pecuniária pelo exercício de cargo público.

Para realizar a atualização dos valores, o vencimento base foi corrigido por meio do Índice Geral dos Preços - Disponibilidade Interna (IGP-DI) para julho de 2017. Em seguida, a remuneração foi comparada com o SMP, o qual, foi calculado utilizando as horas trabalhadas $(\mathrm{H})$ e o salário mínimo (SM) (Decreto ${ }^{\circ} 8.948$ de dezembro de 2016), conforme o art. 5 da Lei n. 4.950-A de 1966:

$$
\operatorname{SMP}(R \$)=\{[(6 \times 1)+(h \times 1,25)] \times(s . m)\}
$$

Os dados coletados foram registrados e analisados em planilhas eletrônicas do Microsoft Excel $2016 \circledR$

\section{RESULTADO E DISCUSSÃO}

A admissão para os cargos técnicos nos órgãos públicos analisados apresentam requisito mínimo, como: diploma de graduação em engenharia de pesca com a indicação do ato de reconhecimento do mesmo junto ao Conselho Nacional ou Estadual de Educação e o registro no Conselho Regional de Engenharia e Arquitetura /PA (CREA/PA). Para os cargos de magistério superior, o profissional precisa ter uma pós-graduação (mestrado/doutorado) na área de recursos pesqueiros/aquícolas ou em área correlatas.

Os editais apresentam cargos conforme a demanda das entidades públicas com carga horária semanal variando entre 30 horas a 40 horas. Em relação aos salários ofertados por estas instituições, todos os seus editais proporcionaram um vencimento base reajustado inferior ao Salário Mínimo Profissional (SMP) do engenheiro de pesca.

O Salário Mínimo Profissional (SMP) é calculado sobre o valor de seis vezes o salário mínimo determinado pelo Governo Federal, para a jornada de seis horas diárias de trabalho, conforme o art. 82 da Lei Federal n 4.950-A de 22 de abril de 1966 (BRASIL,1966), porém, segundo a Resolução do Senado Federal n ${ }^{\circ} 12$ de 1971, os órgãos públicos podem ignorar o SMP estabelecido por lei e utilizar outros critérios de remuneração.

Os processos seletivos apresentam restrições no que diz respeito ao número de vagas ofertadas e à periodicidade. Como previsto, os órgãos públicos municipais e federais propuseram, respectivamente, o menor e maior salário bruto (Tabela 2). 
Tabela 2. Salário Mínimo Profissional (SMP) dos engenheiros de pesca conforme o reajuste do Vencimento Base (VB) apresentados nos editais dos processos seletivos realizados pelos órgãos públicos do setor pesqueiro e aquícola, no estado do Pará, 2017.

\begin{tabular}{|c|c|c|c|c|c|c|}
\hline $\begin{array}{l}\text { Esfera de } \\
\text { governo }\end{array}$ & $\begin{array}{l}\text { Entidade } \\
\text { pública }\end{array}$ & $\begin{array}{c}\text { VB } \\
(\mathbf{R} \$)\end{array}$ & $\begin{array}{c}\mathrm{VB} \\
\text { reajustado } \\
(\mathrm{R} \$)\end{array}$ & $\begin{array}{l}\text { SMP } \\
(\mathbf{R} \$)\end{array}$ & Cargos & $\begin{array}{c}\text { Carga } \\
\text { horária } \\
\text { semanal }\end{array}$ \\
\hline \multirow{8}{*}{ Municipal } & $\begin{array}{c}\text { Prefeitura de São } \\
\text { João da Ponta } \\
\text { (PA) }\end{array}$ & $1.584,00$ & $1.606,53$ & $5.622,00$ & $\begin{array}{l}\text { Engenheiro } \\
\text { de pesca }\end{array}$ & 30 \\
\hline & $\begin{array}{c}\text { Prefeitura de } \\
\text { Bragança (PA) }\end{array}$ & $1.080,00$ & $1.545,56$ & $7.964,50$ & $\begin{array}{c}\text { Engenheiro } \\
\text { de pesca }\end{array}$ & 40 \\
\hline & $\begin{array}{l}\text { Prefeitura de } \\
\text { Óbidos (PA) }\end{array}$ & 960,00 & $1.319,11$ & $7.964,50$ & $\begin{array}{c}\text { Engenheiro } \\
\text { de pesca }\end{array}$ & 40 \\
\hline & $\begin{array}{c}\text { Prefeitura de } \\
\text { Vigia (PA) }\end{array}$ & 900,00 & $1.223,17$ & $7.964,50$ & $\begin{array}{c}\text { Engenheiro } \\
\text { de pesca }\end{array}$ & 40 \\
\hline & $\begin{array}{l}\text { Prefeitura de } \\
\text { Cametá (PA) }\end{array}$ & $1.901,55$ & $2.289,54$ & $5.622,00$ & $\begin{array}{c}\text { Engenheiro } \\
\text { de pesca }\end{array}$ & 30 \\
\hline & $\begin{array}{c}\text { Prefeitura de } \\
\text { Tailândia (PA) }\end{array}$ & $2.000,00$ & $2.408,08$ & $7.964,50$ & $\begin{array}{l}\text { Engenheiro } \\
\text { de pesca }\end{array}$ & 40 \\
\hline & $\begin{array}{l}\text { Prefeitura de } \\
\text { Monte Alegre } \\
\text { (PA) }\end{array}$ & $1.678,00$ & $1.843,96$ & $7.964,50$ & $\begin{array}{c}\text { Engenheiro } \\
\text { de pesca }\end{array}$ & 40 \\
\hline & FUNBOSQUE & $1.492,80$ & $1.898,22$ & $7.964,50$ & $\begin{array}{c}\text { Engenheiro } \\
\text { de pesca }\end{array}$ & 40 \\
\hline \multirow[b]{2}{*}{ Estadual } & EMATER & $1.884,86$ & $3.662,11$ & $7.964,50$ & $\begin{array}{l}\text { Extensionista } \\
\text { rural I) }\end{array}$ & 40 \\
\hline & SEPAq $^{1}$ & 733,83 & $1.283,92$ & $5.622,00$ & $\begin{array}{l}\text { Técnico em } \\
\text { Gestão de } \\
\text { Pesca e } \\
\text { Aquicultura }\end{array}$ & 30 \\
\hline \multirow{5}{*}{ Federal } & UFRA & $3.594,57$ & $4.302,19$ & $7.964,50$ & $\begin{array}{l}\text { Professor } \\
\text { Adjunto }\end{array}$ & 40 \\
\hline & UFPA & $2.318,71$ & $3.206,78$ & $7.964,50$ & $\begin{array}{c}\text { Professor } \\
\text { Adjunto }\end{array}$ & 40 \\
\hline & UFOPA & $4.455,22$ & $4.455,22$ & $7.964,50$ & $\begin{array}{c}\text { Professor } \\
\text { Assistente A }\end{array}$ & 40 \\
\hline & IFPA & $3.594,57$ & $4.020,41$ & $7.964,50$ & $\begin{array}{c}\text { Professor } \\
\text { efetivo }\end{array}$ & 40 \\
\hline & SUDAM & $2.449,98$ & $3.063,87$ & $7.964,50$ & $\begin{array}{c}\text { Engenheiro } \\
\text { de Pesca }\end{array}$ & 40 \\
\hline
\end{tabular}

Conforme o avanço dos ramos emergentes da produção animal, a demanda por mão de obra qualificada nos municípios paraense tende a aumentar. A falta de capacitação dos produtores e a insuficiência de assistência técnica para atender as propriedades aquícolas figuram entre os principais problemas da cadeia produtiva da piscicultura paraense (BRABO, 2014). A ausência 
de concursos públicos e a baixa remuneração estão entre os principais problemas no que se refere à precarização das condições de trabalho (RIBEIRO; GUZZO, 2014).

O âmbito municipal se destaca por agregar maior empregabilidade de profissionais, embora os valores corrigidos dos salários brutos apresentarem uma média de $\mathrm{R} \$ 1.766$, 77. O município de Tailândia merece destaque por apresentar a maior remuneração para engenheiro de pesca no seu edital de processo seletivo. Por outro lado, Bragança, Vigia e Cametá designaram remuneração este profissional aquém do potencial pesqueiro municipal relatado em outros trabalhos (ESPIRITO-SANTO; ISAAC, 2012; BENTES et al., 2012; LUTZ et al.,2016).

Devido apresentar maior afinidade com os problemas da cidade e por ser mais propensa ao controle da sociedade, a administração pública Municipal figura-se como a mais adequada para atender as demandas sociais do município (CAMPELLO; MATIAS, 2000). Porém, a União proporciona recursos insuficientes paras as prefeituras, e consequentemente, comprometem a execução das atividades da cidade (ABRUCIO; COUTO, 1996).

O servidor público municipal tende a se submeter à cargos comissionados e realizar ações administrativas e políticas, uma vez que, a carência de alternativas de acréscimo salarial. No caso das prefeituras visitadas, o adicional varia entre $\mathrm{R} \$ 700,00$ a $\mathrm{R} \$ 1000,00$ por cada função.

O Plano de Carreira, Cargos e Salários (PCCS) orienta os servidores públicos no que diz respeito às possibilidades de ascensão profissional, bem como capacitar a gestão de pessoas, e assim, estimular o desenvolvimento de competências técnicas e estabelecer uma política de remuneração adequada (GONÇALVES; CORRÊA; SANTOS, 2016).

A ausência de um PCC's dificulta a tomada de decisão do gestor público em relação a necessidade da admissão de novos funcionários, a remuneração adequada para cada cargo do órgão público e os benefícios básicos para o técnico (MARTINS, 2017). Este cenário reflete no desalento dos engenheiros pesca em almejar uma autonomia profissional. O PCC's estimula o profissional a executar suas tarefas e melhorar o desempenho da instituição, como ocorre na saúde pública (COSTA et al., 2010) e educação pública (PIMENTEL, PALAZZO e OLIVEIRA, 2009)

O desenvolvimento de um sistema de remuneração adequado com as estratégias da empresa deve objetivar aspectos como atrair e reter talentos, motivar e comprometer pessoal, aumentar a produtividade e qualidade do trabalho desenvolvido, controlando custos laborais, cumprindo a legislação trabalhista e dando tratamento justo e equitativo às pessoas. (CHIAVENATO, 2014).

No âmbito estadual, a Emater/PA destaca-se por agregar a maior remuneração desta esfera de governo, visto que os engenheiros de pesca são celetistas em virtude do vínculo empregatício 
regido pela Consolidação das Leis do Trabalho (CLT). O profissional da Emater exerce a função de extensionista rural e executa outras atividades do ramo agrário, como: bovinocultura, avicultura, caprinocultura, fruticultura e agroindustriais. As variáveis vinculadas à identidade com a carreira, progresso profissional e nível de escolaridade recebem destaque por explicar o comprometimento dos técnicos da Emater/MG. (PINHO; KILIMNIK; ANDRADE, 2015).

Conforme o Regimento Interno Pessoal da instituição (RIP), o salário dos servidores da EMATER-PA é composto por salário fixado no Plano de Carreira, Cargos, Salários, Benefícios e Vantagens (PCCSBV) e possui registro em Carteira de Trabalho. Dessa forma, apresenta uma maior dedução fiscal, como: horas extras, Imposto de Renda (IR), Fundo de Garantia do Tempo de Serviço (FGTS), entre outros (PARÁ, 2013; ADORNO JÚNIOR; SOARES, 2016).

Existe duas alternativas para aumento salarial da Emater: por tempo de serviço que ocorre anualmente e pelo desempenho curricular dos funcionários concedendo um aumento de $20 \%$ a $40 \%$ do vencimento base. $\mathrm{O}$ aperfeiçoamento profissional pode assegurar o ingresso na carreira via concurso público de provas e títulos, remuneração apropriado; progressão funcional e maior estímulo nas suas tarefas (FERREIRA, GUTIERRES; CARNEIRO, 2017).

Entretanto, não há concursos públicos para cargos efetivos há mais de uma década nesta instituição no estado do Pàrá, o que reflete na insuficiência técnica para atender o setor produtivo estadual. A participação dos extensionistas é fundamental para o sucesso do agronegócio (OSTRENSKY; BOEGER, SOTO, 2008). Entretanto, o estado do Pará não possui não possui um contingente suficiente de técnicos com formação especializada em piscicultura para atender a demanda da atividade (BRABO, 2014).

Este cenário desfavorável se expande quando se analisa outros órgãos públicos estaduais competentes. A instituição pública estadual que abordava assuntos exclusivos da pesca e aquicultura, a Secretaria Estadual de Pesca e Aquicultura (SEPAq), se integrou à Secretaria de Agricultura e originou na SEDAP. Com isso, atualmente o departamento dos recursos pesqueiros e aquícolas compartilha os recursos financeiros com outras atividades agrárias. Dessa forma, a abertura de novos processos seletivos é dubitável.

As alternativas de incremento salarial dos engenheiros de pesca da atual SEDAP ocorrem pelo exercício dos cargos de Direção e Assessoramento Superior (DAS) em que há o aumento da remuneração de $90 \%$ a $95 \%$, outrossim, há a possibilidade do profissional ter adicional por função gratificada e tempo de serviço.

Em relação as consequências da extinção da SEPAq, pode-se destacar a redução do quadro de funcionários técnicos e a restrição de recursos financeiros, o que inviabiliza a execução de projetos técnicos e as visitas nas unidades produtivas/comunidades pesqueiras (VIANA et al., 
2016). A piscicultura poderia ter um avanço, se estes órgãos públicos do Estado disponibilizassem assistência técnica efetiva aos produtores (MELO et al., 2010).

No âmbito federal, a remuneração em IES demonstra um perceptível crescimento salarial ao longo dos anos e há novos cursos de engenharia de pesca sendo criados, como é o caso da UFOPA, o que representa na valorização da área. Os docentes Engenheiros de Pesca agregam valores entre $\mathrm{R}$ \$ 4.000,00 a R \$ 11.000,00 entre a discrepância entre os salários ocorreu devido o tempo de serviço dos profisssionais ser considerado no cálculo da remuneração.

A criação de novos cursos vinculados ao setor aquícola e pesqueiro é consequência de políticas públicas propícias para a expansão e interiorização do ensino superior brasileiro, como o Programa de Apoio a Planos de Reestruturação e Expansão das Universidades Federais (REUNI) (ZAGO; PAIXÃO; PEREIRA, 2016). Em relação aos adicionais que proporcionam grandes diferenças entre os salários dos docentes, o tempo de serviço na IES acrescentar de 70\% a 90\% do vencimento base conforme o período de atuação na instituição (CLARO; PROFETA, 2015)

O valor salarial dos professores dispõe do Plano de Carreira e Cargos do Magistério Federal (PCCMF) que foi reestruturado por meio da Lei Federal $\mathrm{n}^{\circ} 12.772$, de 28 de dezembro d e 2012 a fim de promover a consolidação dos docentes de nível federal (BRASIL, 2012). Entre as promoções e progressões expostas no PCCMF, a sucessão na carreira por titulação (cursos de licenciaturas curta ou plena e em cursos da pós-graduação lato sensu ou stricto sensu), o salário inicial para professores com doutorado $(\mathrm{R} \$ 8.400,00)$ e o exercício da profíssão como dedicação exclusiva merecem destaque.

A liberdade acadêmica agregada de concorrência e meritocracia intelectual é um estímulo para os professores proporcionarem aos alunos uma educação de qualidade. (ALTABACH, 2013). Dessa forma, é necessário oferecer condições adequadas para o desenvolvimento profissional dos docentes, tendo em vista que este profissionais é peça fundamental na formação e capacitação dos novos engenheiros de pesca (JACOMINI; PENNA, 2016).

Conforme a Lei Federal n. 8.112 de 11 de dezembro de 1990, o servidor pode afastar-se da função do cargo efetivo, com a respectiva remuneração, para participar em programa de pósgraduação stricto sensu em IES no País (BRASIL, 1990). Esta situação incide nas escolhas dos egressos em engenharia de pesca em seguir a direção acadêmica a fim de realizar uma pósgraduação ampliando a quantidade de pesquisadores.

Devido ao número elevado de egressos na carreira acadêmica, o cenário de que não haver uma demanda no mercado para os extensionistas se destaca. Embora exista uma carência de profissionais capacitados no setor produtivo paraense (BRABO et al., 2014). Entretanto, o problema se inicia ainda fase de graduação onde a formação universitária é insuficiente para atender a demanda requerida no mercado de trabalho. Dentre as alternativas para viabilizar a 
integração entre aprendizado teórico e prático, o estágio obrigatório e as empresas juniores merecem destaque por proporcionar essa experiencia profissional ainda no processo de formação (GONDIM, 2002).

De acordo com a lei no 4.950-A de 1966, o salário-base obrigatório para o engenheiro de pesca é proporcional à jornada de trabalho, sendo seis vezes o salário mínimo nacional para jornada de 6 (seis) horas diária e, em caso de horas excedente, é adicionado $25 \%$ sob do valor da hora de trabalho para aquelas superiores à sexta hora do dia. O Decreto de $n^{\circ} 88.911$ de 24 de outubro de 1983 ratifica o enquadramento profissional e intensifica a legitimidade à profissão englobando-a em atividades de nível superior de natureza especializada (BRASIL, 1983).

Por outro lado, conforme a resolução do Senado Federal n. 12 de 1971, a aplicação da Lei n. 4950-A de 1966 que dispõe sobre os vencimentos (salários) dos servidores públicos estatutários foi suspensa em virtude da matéria remuneração na esfera administrativa direta (autarquias e fundações) ser de competência exclusiva do Executivo, conforme definido na Constituição Federal. Ou seja, o órgão público assume papel definitivo na determinação do salário quem define é o órgão.

Embora que a resolução n. 397 de 11 agosto de 1995 assegura e responsabiliza os conselhos regionais a fiscalização (no caso dos engenheiros de pesca, o CREA) do cumprimento do salário mínimo profissional àqueles com vínculo empregatício (BRASIL, 1995), o art. 37, inciso 169 , parágrafo $1^{\circ}$, da Constituição Federal garante legalmente às instituições públicas a remuneração de seus servidores diferente do mínimo profissional para os órgãos que apresentem lei específica de orçamento prévio com projeções de despesas de quadro e salário próprio (BRASIL, 1988).

Com isso, as organizações sociais (Federação dos Engenheiros de Pesca (FAEP) e a Associação dos Engenheiros de Pesca do Pará) precisam ser mais atuantes para defender os interesses no CREA/PA e nas três esferas de governo, em aspectos profissionais e políticos. Atualmente, o CREA/PA possui 304 engenheiros de pesca registrados, dos quais, 113 apresentam anuidades quitadas que reflete no fracasso conquistarreivindicações acerca da representatividade profissional.

Portanto, é fundamental que os engenheiros de pesca do estado do Pará se registrem no Conselho Regional de Classe para aumentar o poder de solicitar mudanças em legislações especificas sobre o aumento do piso salarial, implantação de plano de carreira, cargos e salário e outros benefícios trabalhistas. 


\section{CONCLUSÃO}

Os engenheiros de pesca estão presentes nos principais órgãos públicos competentes do setor aquícola e pesqueiro que atuam no estado do Pará, porém possuem remunerações abaixo do estabelecido em Lei e a maioria das instituições não aderem estratégias que possa aumentar o salário.

As disparidades entre as remunerações nas esferas públicas paraenses estão muito além do reconhecimento profissional dos engenheiros de pesca, mas sim da ausência ou ineficiência de um planejamento estratégico para aproveitar da melhor maneira a produtividade destes profissionais.

\section{REFERÊNCIAS}

ABRUCIO, F.; COUTO, C. A. A redefinição do papel do estado no âmbito local. São Paulo em perspectiva, São Paulo/SP, v. 10, n. 3, p. 40-47, jul./set. 1996.

ALBRECHT, P. A. T.; KRAWULSKI, E. Concurseiros e a busca por um emprego estável: reflexões sobre os motivos de ingresso no serviço público. Cadernos de Psicologia Social do Trabalho, São Paulo/SP, v. 14, n. 2, p. 211-226, mar.jun. 2011.

ALMEIDA, N. M.; SALES, L. T.; SOARES, M. C. F. Perfil do engenheiro de pesca do Brasil. Revista Brasileira de Engenharia de Pesca, São Luís, v. 2, n. 3, p. 57-68, set./out. 2009.

ALTBACH, P. Os papéis complexos das universidades no período de globalização. GUNI. Educação superior em um tempo de transformação: novas dinâmicas para a reponsabilidade social. Porto Alegre: EDIPUCRS, 2013.

ARAÚJO, L. A. D.; MAIA, M. Inclusão e concurso público: análise crítica da jurisprudência sobre pessoas com deficiência. Revista de Direito Administrativo e Constitucional, Belo Horizonte/MG, v. 16, n. 65, p. 135-157, jul./set. 2017.

BENTES, B.et al. Multidisciplinary approach to identification of fishery production systems on the northern coast of brazil. Biota Neotropica, Campinas/SP, v. 12, n. 1, p. 81-92, jan./mar. 2012.

BRABO, M. F.et al. Competitividade da cadeia produtiva da piscicultura no Nordeste paraense sob a perspectiva dos extensionistas rurais. Informações Econômicas. São Paulo/SP, v. 44, n. 5, p. 1-13, nov./dez. 2014.

BRABO, M. F. Piscicultura no Estado do Pará: situação atual e perspectivas. Acta of Fisheries and Aquatic Resources, v. 2, n. 1, p. 1-7, jan. /mar. 2014.

BRASIL, Ministério da Pesca e Aquicultura (MPA). Censo aquícola nacional, ano 2008. Brasília/DF: República Federativa do Brasil, 2013, 336p.

BRASIL. Constituição da República Federativa do Brasil de 1988. Brasília/DF. 5 de out. de 1988 
BRASIL. Decreto Lei ${ }^{\circ} 221$, de 28 de fevereiro de 1967. Dispõe sôbre a proteção e estímulos à pesca e dá outras providências. Diário Oficial da União. Brasília/DF, 28 de fev. 1967.

BRASIL. Decreto ${ }^{\circ} 88.911$, de 24 de outubro de 1983. Inclui categoria funcional no GrupoOutras Atividades de Nível Superior, a que se refere a Lei no 5.645, de 10 de dezembro de 1970, e dá outras providências. Diário Oficial da União. Brasília/DF, 24 de out. 1983.

BRASIL. Lei $\mathrm{n}^{\circ}$ 12.772, DE 28 DE DEZEMBRO DE 2012. Dispõe sobre a estruturação do Plano de Carreiras e Cargos de Magistério Federal. Diário Oficial da União. Brasília/DF. 28 de dez. 2012.

BRASIL. Lei n ${ }^{\circ}$ 4.950-A, de 22 de abril de 1966. Dispõe sobre a remuneração de profissionais diplomados em Engenharia, Química, Arquitetura, Agronomia e Veterinária. Senado Federal, Brasília/DF, 7 de jun. 1971.

BRASIL. Lei no 8.112, de 11 de dezembro de 1990. Dispõe sobre o regime jurídico dos servidores públicos civis da União, das autarquias e das fundações públicas federais. Diário Oficial da União. Brasília/DF. 18 de abr. 1991.

CAVALCANTE, M. V. S.; LIMA, T. C. S. A precarização do trabalho na atenção básica em saúde: relato de experiência. Argumentum, Vitória/ES, v. 5, n.1, p. 235-256, jan. /jun. 2013.

CHIAVENATO, I. Gestão de pessoas: e o novo papel dos recursos humanos nas organizações. 4. ed. Barueri, SP: Manoele, 2014.

CLARO, J. A. C. S.; PROFETA, R. A. Programas de benefícios sociais para docentes no ensino superior brasileiro como forma de reter talentos: um estudo exploratório, Avaliação,

Sorocaba/SP, v. 20, n. 1, p. 189-223, mar. 2015.

CONFEA. Resolução no 279, de 15 de junho de 1983. Discrimina as atividades profissionais do engenheiro de pesca. Diário Oficial da União. Brasília/DF, 15 de jun. 1983.

COSTA, A. C. O.et al. Plano de carreira, cargos e salários: ferramenta favorável à valorização dos recursos humanos em saúde pública. Odontologia Clínico-Científica, Recife/PE, v. 9, n. 2, p. 119-123, abr./jun. 2010.

DE-CARVALHO, H. R.; SOUSA, R. A. L.; CINTRA, I. H. A. A aquicultura na Microrregião do Guamá, Pará, Amazônia Oriental, Brasil. Revista de Ciências Agrárias, Belém/PA, v. 56, n. 1, p. 1-6, mar./abr. 2013.

ESPÍRITO-SANTO, R. V.; ISAAC, V. J. Desembarques da pesca de pequena escala no município de Bragança-PA, Brasil: esforço e produção. Boletim do Laboratório de Hidrobiologia, São Luís/MA, v. 25, n. 1, p. 31-45, jan./ mar. 2012.

FERNANDES, M. D. E.et al. Remuneração de professores de educação básica nos setores público e privado na esfera municipal. Educação e Pesquisa, São Paulo, v. 44, Seção: Artigos, 2018

FERREIRA, D. M.; GUTIERRES, D. V. G.; CARNEIRO, A. P. S. O processo de construção e aprovação do plano de carreira dos profissionais do magistério da rede estadual de ensino do estado do Pará. Revista Educação e Emancipação, São Luís, v. 10, n. 1, jan./abr. 2017. 
FREITAS LUTZ, Í. A.et al. Produção pesqueira desembarcada em um estuário do norte do Brasil (Bragança, Pará). Acta of Fisheries and Aquatic Resources, São Cristovão/SE, v. 4, n. 2, p. 125-136, mai. /jun. 2016.

GONÇALVES, W. A.et al. O Sistema de Remuneração e Recompensas: um estudo bibliométrico. Revista de Carreiras e Pessoas. São Paulo/SP, v. 6, n. 2, p. 138-156, mar./jun. 2016.

IBGE - Instituto Brasileiro de Geografia e Estatística. Estimativa populacional 2016. Rio de Janeiro: IBGE. 2016b

IBGE - Instituto Brasileiro de Geografia e Estatística. Produção da Pecuária Municipal Brasil - 2015. Rio de Janeiro: IBGE. 2016

IBGE - Instituto Brasileiro de Geografia e Estatística. Produção da Pecuária Municipal Brasil - 2016. Rio de Janeiro: IBGE. 2017.

JACOMINI, M. A.; PENNA, M. G. O. Carreira docente e valorização do magistério: condições de trabalho e desenvolvimento profissional. Pro-Posições, Campinas/SP, v. 27, n. 2, p. 177-202, mai./ago. 2016.

JÚNIOR, H. L. A.; SOARES, M. C. P. Os setenta anos da Consolidação das Leis do Trabalho e os vinte e cinco anos da Constituição Federal Brasileira: avanços sociais no Direito do Trabalho. UNIVERSITAS, Mogi-Mirim/SP, v. 9, n. 17, p. 137-157, jan./jun. 2016.

KUBITZA, F. Aquicultura no Brasil: Principais espécies, áreas de cultivo, rações, fatores limitantes e desafios. Panorama da Aquicultura, v. 25, n. 132, p. 10-23, 2015.

LEE, J.; SARPEDONTI, V. Diagnóstico, tendência, potencial e políticas públicas para o desenvolvimento da aquicultura. In: Diagnóstico da pesca e da aquicultura no Estado do Pará, Belém: Universidade Federal do Pará / Núcleo de Altos Estudos Amazônicos, v. 6, n. 8. 2008, p. 823-932

LIMA, C. C. J.; Produtividade nas obras elétricas nos terminais e refinarias de petróleo da Petrobrás. In: XXVIII Encontro Nacional de Engenharia de Produção, Rio de Janeiro/RJ, 2008. Anais... Rio de Janeiro: ENEGEP, 2008, p. 1-11.

LIMA, T. C. B.et al. Percepção de sucesso na carreira: semelhanças e diferenças entre profissionais do setor público. Revista de Carreiras e Pessoas, São Paulo/SP, v. 5, n. 1, p. 1833, jan. /mar. 2015

MACEDO, D. F.et al. Análise do Concurso Público como instrumento de Seleção de pessoal no setor público: percepção de um grupo de servidores de Instituições Federais de Ensino Superior. Sociais e Humanas, Santa Maria/RS, v. 29, n. 1, p. 92 - 110, jan./abr. 2016.

MARTINS, M. L. A importância da implementação do plano de cargos e salários para a atuação da gestão de pessoas nas organizações: o caso de uma instituição de ensino superior de médio porte. Revista Facthus de Administração e Gestão, Uberaba/MG, v. 1, n. 1, p. 122-144, jan./mar. 2017.

MATIAS, A. B.; CAMPELLO, C. A. Administração financeira municipal. São Paulo/SP: Atlas, 2000 
MELO, C.et al. Diagnóstico da piscicultura na mesorregião Sudeste do Estado do Pará. Boletim Técnico-Científico do Cepnor, Belém/PA, v. 10, n. 1, p. 55-65, jan./ mar. 2010.

O’ DE ALMEIDA JÚNIOR, C. R. M.; SOUZA, R. A. L. Aquicultura no Nordeste paraense, Amazônia Oriental, Brasil. Boletim Técnico Científico do CEPNOR, Belém, v. 13, n. 1, p. 33 42, 2013.

OSTRENSKY, A.; BORGHETTI, J. R.; SOTO, D. Estudo setorial para consolidação de uma aquicultura sustentável no Brasil. Grupo Integrado de Aquicultura e Estudos Ambientais, Curitiba: SEAP. 2007. 287p.

PARÁ. Empresa de Assistência Técnica e Extensão Rural do Estado do Pará (EMATER). Regimento Interno de Pessoal. Marituba/PA, 2013, 63p.

PIMENTEL, G. S. R.; PALAZZO, J.; OLIVEIRA, Z. D. R. B. B. Os planos de carreira premiam os melhores professores. Ensaio: Avaliação e Políticas Públicas em Educação, Rio de Janeiro, v. 17, n. 63, p. 355-380, abr./jun. 2009.

PINHO, E. C. S. N.; KILIMNIK, Z. M.; ANDRADE, D. F. A influência da estrutura matricial no comprometimento com a carreira em comparação com a estrutura tradicional: um estudo de caso na EMATER-MG. REGE-Revista de Gestão, São Paulo/SP, v. 22, n. 2, p. 223-239, abr./jun. 2015 .

RIBEIRO, M. E.; GUZZO, R. S. L. Psicologia no Sistema Único de Assistência Social (SUAS): reflexões críticas sobre ações e dilemas profissionais. Pesquisas e Práticas Psicossociais, São João del Rei/MG, v. 9, n. 1, p. 83-96, jan./jun., 2014.

SILVA, E. G.et al.Análise das causas do atraso na remuneração dos profissionais de educação no município de Ouricuri-PE. Id online Revista Multidisciplinar e de Psicologia, Juazeiro do Norte/CE, v. 11, n. 36, p. 313-326, Jul. 2017.

SOARES, L. A. C. F.et al.Plano de carreiras, cargos e salários (PCCS) e motivação dos Trabalhadores em saúde: a percepção dos funcionários da Secretaria Municipal de Saúde de Manaus. Revista de Administração Hospitalar, Belo Horizonte/MG, v. 10, n. 1, p. 61-74, jan./mai. 2013.

SOARES, M. C. F.; HAZIM, F. H. V.; A Engenharia de Pesca no Brasil: Trajetória de 40 anos. 1. ed. Recife-PE: Editora Recife, 2010.

UMBURANAS, R. C.et al.Imagem da população guarapuavana a respeito das atividades profissionais desenvolvidas pelo engenheiro agrônomo. In: $3^{\circ}$ Salão de Extensão e Cultura, Guarapuava/PR, 2010. Anais...Guarapuava: UNICENTRO, 2010, p. 1-8.

VÉLEZ, C. A.; GALEANO, L. F.; GAVIRIA, C. Diagnóstico del perfil ocupacional y competencias del Zootecnista en el Departamento de Antioquia, Colombia. Revista Colombiana de Ciencias Pecuarias, Antioquia, v. 23, n. 1, p. 86-98, jan./mar. 2010. 